\title{
Thermodynamics of binding of divalent magnesium and manganese to uridine phosphates: implications for diabetes-related hypomagnesaemia and carbohydrate biocatalysis Corbin J Zea, Gulden Camci-Unal and Nicola L Pohl*
}

Address: Department of Chemistry and the Plant Sciences Institute, Iowa State University, Gilman Hall, Ames, IA, 50011-3111, USA

Email: Corbin J Zea - czea@gvc.edu; Gulden Camci-Unal - gcu@iastate.edu; Nicola L Pohl* - npohl@iastate.edu

* Corresponding author

Published: I 5 July 2008

Chemistry Central Journal 2008, 2:15 doi:10.1186/1752-153X-2-15

This article is available from: http://journal.chemistrycentral.com/content/2/1/15

(c) 2008 Zea et al

This is an Open Access article distributed under the terms of the Creative Commons Attribution License (http://creativecommons.org/licenses/by/2.0), which permits unrestricted use, distribution, and reproduction in any medium, provided the original work is properly cited.

\begin{abstract}
Background: Although the necessity of divalent magnesium and manganese for full activity of sugar nucleotidyltransferases and glycosyltransferases is well known, the role of these metal cations in binding the substrates (uridine 5 '-triphosphate, glucose-I-phosphate, $\mathrm{N}$-acetylglucosamine-Iphosphate, and uridine 5'-diphosphate glucose), products (uridine 5'-diphosphate glucose, uridine 5 '-diphosphate $\mathrm{N}$-acetylglucosamine, pyrophosphate, and uridine 5'-diphosphate), and/or enzyme is not clearly understood.
\end{abstract}

Results: Using isothermal titration calorimetry we have studied the binding relationship between the divalent metals, magnesium and manganese, and uridine 5'-phosphates to determine the role these metals play in carbohydrate biosynthesis. It was determined from the isothermal titration calorimetry (ITC) data that $\mathrm{Mg}^{+2}$ and $\mathrm{Mn}^{+2}$ are most tightly bound to $\mathrm{PP}_{i}, \mathrm{~K}_{\mathrm{b}}=4 \mathrm{I}, 000 \pm 2000 \mathrm{M}^{-1}$ and 28,000 $\pm 50,000 \mathrm{M}^{-1}$ respectively, and UTP, $\mathrm{K}_{\mathrm{b}}=14,300 \pm 700 \mathrm{M}^{-1}$ and $13,000 \pm 2,000 \mathrm{M}^{-1}$ respectively.

Conclusion: Our results indicate that the formal charge state of the phosphate containing substrates determine the binding strength. Divalent metal cations magnesium and manganese showed similar trends in binding to the sugar substrates. Enthalpy of binding values were all determined to be endothermic except for the $\mathrm{PP}_{i}$ case. In addition, entropy of binding values were all found to be positive. From this data, we discuss the role of magnesium and manganese in both sugar nucleotidyltransferase and glycosyltransferase reactions, the differences in metal-bound substrates expected under normal physiological metal concentrations and those of hypomagnesaemia, and the implications for drug design.

\section{Background}

The roles that nucleotides play in cellular metabolism range in scope from their use as enzyme substrates to regulators for numerous biochemical pathways. Because of their biological importance and the requirement of divalent metals for biological activity, the binding relationship between various metals and nucleotides has been well documented to shed light on the role of metal-nucleotide complexes in the conformational changes that occur in DNA biosynthesis [1-4] and the energy pathways that involve ATP [5-12]. 
Recent studies suggest that certain metabolic disorders are linked to serum magnesium concentrations in a way that can be partially explained by these relative metal-binding equilibria. For example, individuals with hypomagnesaemia - reduced serum magnesium concentration - have an increased incidence of metabolic disorders such as type 2 diabetes mellitus [13-20] and high blood pressure [13]. Simple oral administration of magnesium chloride can increase serum magnesium concentrations and decrease total cholesterol and HDL levels while increasing LDL and insulin sensitivity in these patients [21-23]. In patients with high cholesterol and hypomagnesaemia, magnesium treatment is attributed to increasing the effectiveness of statin pharmaceuticals by shifting the equilibrium to the formation of a $\mathrm{Mg}^{+2}$-ATP complex which is a necessary intermediate in the cholesterol biosynthetic pathway [24]. Surprisingly, searches for an explanation of the effect of magnesium supplementation on insulin levels so far have focused only on metal effects at the DNA level [1] and not on the effects of metals on the relative amounts of the substrates involved in glucose metabolism. Such discussions are hindered by the lack of reports of the magnesium binding affinities to these substrates.

The biochemical pathway that synthesizes glycogen and degrades it (Scheme 1) plays an important role in cellular function and metabolism. This pathway is responsible for the storage of glucose and glycogen as well as the regulation of blood glucose levels. For this reason glycogen synthase as well as phosphorylase $b$ have been targets of diabetic drug targets [25-28]. It has also been shown that the biocatalyst that activates glucose as ADP-glucose in plants plays a regulatory role in starch biosynthesis [2931] which tags all three biocatalysts as contributing to the regulation of glucose concentrations.
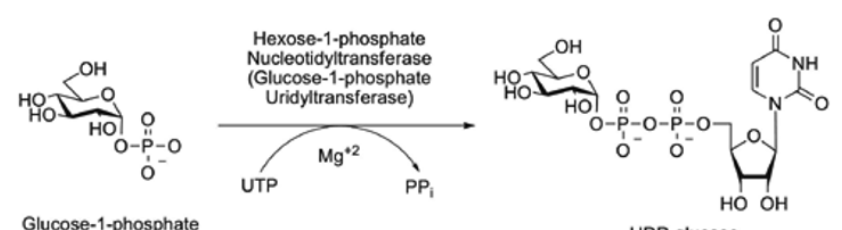

Glucose-1-phosphate

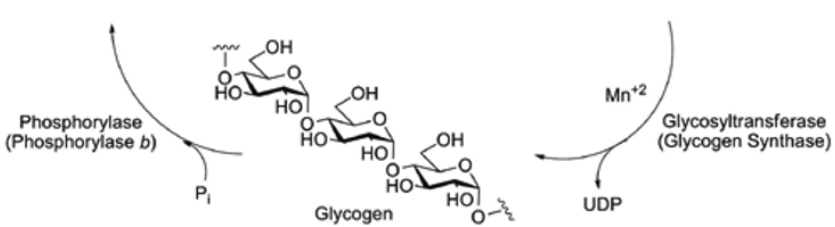

Scheme I: Biochemical pathway for the synthesis and degradation of glycogen. General classification and the specific names of biocatalysts associated with carbohydrate biosynthesis are shown.

While it is widely known that divalent cations, in particular $\mathrm{Mg}^{+2}$ and $\mathrm{Mn}^{+2}$, play a very important role in carbohydrate biocatalysis, the actual mechanism by which the metal interacts with the ligand and the enzymes is not clearly understood. This has important implications in drug development; whether the cation generally binds tightly to the protein active site or binds to the ligand before ligand binding to the protein is an important consideration in designing effective inhibitors of this interaction. It is well documented that uridine triphosphate (UTP), pyrophosphate $\left(\mathrm{PP}_{i}\right)$, glucose-1-phosphate (Glc-1$\mathrm{P})$, and uridine diphosphate glucose (UDP-Glc) all bind and act as inhibitors [32-35], whereas uridine diphosphate (UDP) was demonstrated by Gillett and coworkers [36] to not bind to UDP-Glc pyrophosphorylase. This result is confusing since other researchers have determined UDP to be an inhibitor of UDP-Glc pyrophosphorylase $[33,34]$. This raises the question of how inhibitor binding is related to inhibitory affect. Herein, we discuss the binding of $\mathrm{Mg}^{+2}$ and $\mathrm{Mn}^{+2}$ with UTP, UDP, uridine monophosphate (UMP), UDP-Glc, and $\mathrm{PP}_{i}$ in order to gain an understanding in how and why sugar nucleotidyltransferases and glycosyltransferases (type B) are metal dependant, and to determine in what order metal binding occurs (i.e. does the metal bind to the ligand or biocatalyst first) and what role that has on catalytic activity or inhibition.

\section{Results and discussion}

While the binding of $\mathrm{Mg}^{+2}$ to nucleotide phosphates has been studied previously $[5,7,11]$, the binding relationship between the metals, $\mathrm{Mg}^{+2}$ and $\mathrm{Mn}^{+2}$, and uridine phosphates have not been described. Because the primary interaction between the metal and nucleotides occurs between the phosphates and the metal one would expect the binding parameters between ATP and UTP to be similar. It would also be expected that little binding would be lost by the addition of glucose to UDP to form UDP-glucose. To address these questions, we determined the thermodynamics of binding of $\mathrm{Mg}^{+2}$ and $\mathrm{Mn}^{+2}$ to UTP, UDP, UMP, UDP-Glc, Glc-1-P, Glc, U, and $\mathrm{PP}_{i}$ at the physiologically relevant temperature of $37^{\circ} \mathrm{C}$ using isothermal titration calorimetry (ITC) by the direct titration of a solution of magnesium or manganese (II) chloride into a solution containing the phosphate containing compound being studied (Figure 1). It was determined from the ITC data that $\mathrm{Mg}^{+2}$ and $\mathrm{Mn}^{+2}$ are most tightly bound to $\mathrm{PP}_{i^{\prime}} \mathrm{K}_{\mathrm{b}}=$ $41,000 \pm 2000 \mathrm{M}^{-1}$ and $28,000 \pm 50,000 \mathrm{M}^{-1}$ respectively, and UTP, $K_{b}=14,300 \pm 700 \mathrm{M}^{-1}$ and 13,000 $\pm 2,000 \mathrm{M}^{-}$ ${ }^{1}$ respectively (Figure 2 ). The binding parameters determined for the binding of $\mathrm{Mg}^{+2}$ and $\mathrm{Mn}^{+2}$ to UDP and UMP were found to be less than that of UTP. The degree of association between $\mathrm{Mg}^{+2}$ and $\mathrm{Mn}^{+2}$ decreases as phosphates are removed (UTP > UDP > UMP). However, as expected, the binding parameters measured were comparable to previously reported results for the binding of $\mathrm{Mg}^{+2}$ to ATP, ADP, AMP, and UMP [1,5-7]. In addition, as expected, there was no measurable binding of $\mathrm{Mg}^{+2}$ and $\mathrm{Mn}^{+2}$ to glu- 


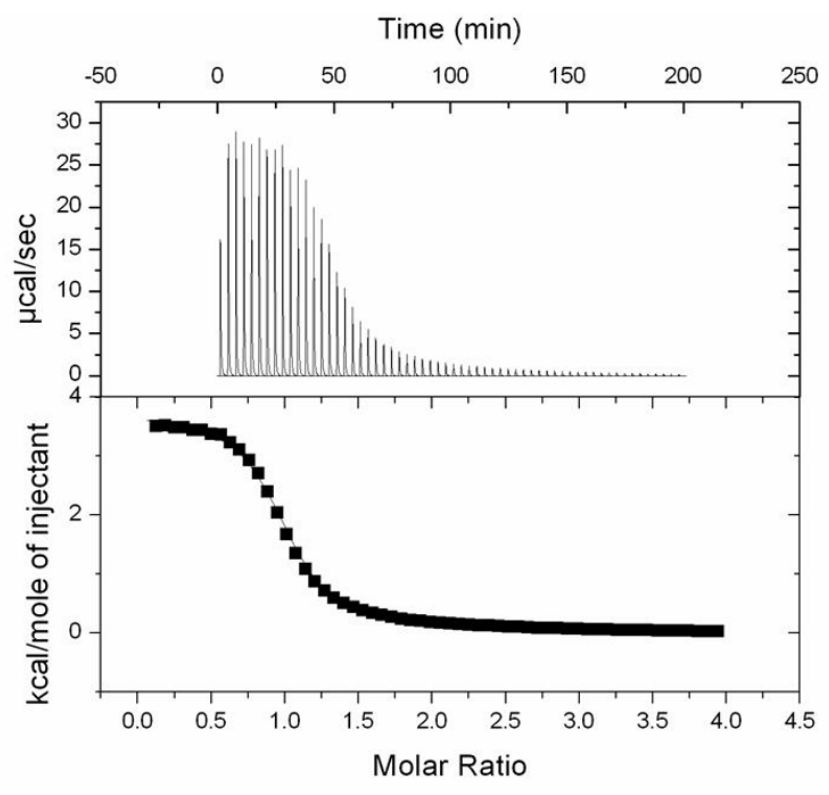

Figure I

Thermogram (top) and binding isotherm (bottom) showing the addition of $75 \mathrm{mM} \mathrm{MgCl}$ (syringe) into $2.1 \mathrm{mM}$ UTP (cell) in $100 \mathrm{mM}$ HEPES at $\mathrm{pH} 7.6$ and $37^{\circ} \mathrm{C}$.

cose and uridine which do not contain negatively charged phosphates.

Comparison of the binding constants for the binding of $\mathrm{Mg}^{+2}$ and $\mathrm{Mn}^{+2}$ to UDP-Glc to the binding of $\mathrm{Mg}^{+2}$ and $\mathrm{Mn}^{+2}$ to UDP affords an approximately 10-fold decrease in binding. This significant decrease in binding due to the addition of glucose was not expected; UDP-Glc is often drawn directly bound to these divalent metals. In contrast, the binding values associated with the binding of $\mathrm{Mg}^{+2}$ and $\mathrm{Mn}^{+2}$ to Glc-1-P were found to be similar in strength to the binding of $\mathrm{Mg}^{+2}$ and $\mathrm{Mn}^{+2}$ to UMP. This data suggests that the binding of $\mathrm{Mg}^{+2}$ and $\mathrm{Mn}^{+2}$ to phosphates is dependent on the binding environment of the phosphates involved in the coordination of the metals, $\mathrm{Mg}^{+2}$ and $\mathrm{Mn}^{+2}$. For comparison, binding affinities to $\mathrm{N}$-acetylglucosamine, N-acetylglucosamine-1-phosphate, and uridine 5'-diphosphate $N$-acetylglucosamine were also measured. From the binding constants the following pattern of affinities emerges: $\mathrm{PP}_{i}>\mathrm{UTP}>\mathrm{UDP}>\mathrm{UMP} \approx \mathrm{UDP}-$ Glc $\approx$ Glc-1-P $\approx$ GlcNAc-1-P > UDP-GlcNAc. This data demonstrates a great effect on metal affinities upon substitution at phosphate. If the phosphate has no substituents covalently bound, as in the case of $\mathrm{PP}_{i}$, the binding constant is large. However, in the case of UMP, UDP-Glc, and Glc-1-P, in which the substrate is bound directly to the binding phosphate, the binding constant is significantly smaller. Finally, in the examples of substrates not having phosphate groups present, GlcNAc, Glc and U, the

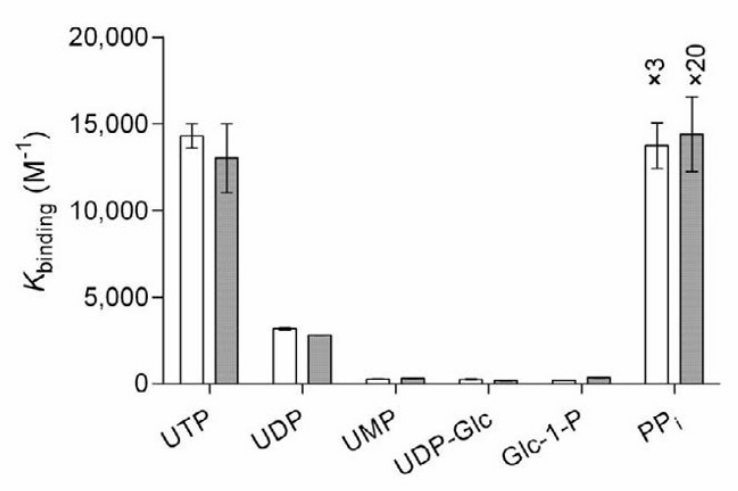

Figure 2

Binding constants of phosphates bound to $\mathrm{Mg}^{+2}$ (white) and $\mathrm{Mn}^{+2}$ (gray).

binding of $\mathrm{Mg}^{+2}$ and $\mathrm{Mn}^{+2}$ to the substrates was so weak as to preclude accurate binding affinity determinations, which indicates the importance that the charged phosphates play in binding divalent metals.

Thermodynamic values for the titrations were determined and for all cases, except for the titration of pyrophosphate by $\mathrm{Mg}^{+2}$ and $\mathrm{Mn}^{+2}$, the binding enthalpies were endothermic. All titrations afforded a positive change in entropy, which correlates to an increase in disorder caused by the loss of a water shell around the metal and phosphate compound as the metal coordinates to the phosphate compound. This increase in disorder allowed the overall coordination of $\mathrm{Mg}^{+2}$ and $\mathrm{Mn}^{+2}$ to the phosphate to be thermodynamically allowed with the free energy following a similar pattern as the binding values $\left(\mathrm{PP}_{i}>\mathrm{UTP}>\right.$ UDP $>$ UMP $\approx$ UDP-Glc $\approx$ Glc-1-P $\approx$ GlcNAc-1-P $>$ UDPGlcNAc).

Although $\mathrm{Mg}^{+2}$ and $\mathrm{Mn}^{+2}$ bind at very similar strengths to phosphates, the intracellular concentrations of $\mathrm{Mg}^{+2}$ and $\mathrm{Mn}^{+2}$ vary greatly. Although metal concentrations can vary depending on cell state, type, and organelle, given intracellular concentrations of $\mathrm{Mg}^{+2}$ and $\mathrm{Mn}^{+2}$ of $1.5 \mathrm{nM}$ [37] and $10 \mathrm{nM}$ [38] respectively, the amount of phosphate expected to be bound to $\mathrm{Mg}^{+2}$ and $\mathrm{Mn}^{+2}$ varies greatly as shown in Figure 3. At these physiological metal concentrations, the concentration of $\mathrm{Mn}^{+2}$ is not large enough to shift the equilibrium of binding in the direction of metalphosphate complex formation. However, all of the phosphates show a measurable degree of binding to $\mathrm{Mg}^{+2}$ at intracellular concentrations of $\mathrm{Mg}^{+2}$. Uridine triphosphate and $\mathrm{PP}_{i}$ are almost completely bound (> 95\%) to $\mathrm{Mg}^{+2}$ at intracellular concentrations of $\mathrm{Mg}^{+2}$, while UDP is mostly 


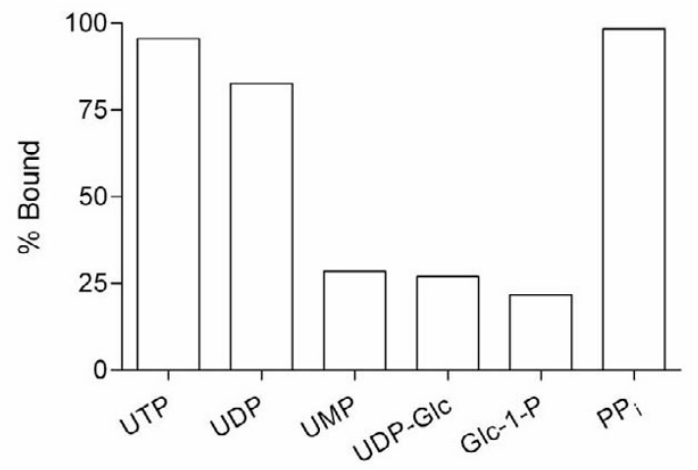

Figure 3

Percent of phosphate bound to $\mathrm{Mg}^{+2}$ (white) at the intracellular concentration of $1.5 \mathrm{mM}$. No measurable binding is observed for $\mathrm{Mn}^{+2}$.

bound (83\%), and UMP, UDP-Glc, and Glc-1-P are only partially bound to $\mathrm{Mg}^{+2}(\sim 25 \%)$.

When the concentration of magnesium decreases, as is the case in hypomagnesaemia $\left(0.7 \mathrm{mM} \mathrm{Mg}^{+2}\right)$ there can be significant changes in the phosphate-magnesium concentration (Figure 4). In cases where $\mathrm{Mg}^{+2}$ is tightly bound, $\mathrm{PP}_{i}$ and UTP, there is not a large change in complex formation. However, when the binding is not as tight, as is the case with UDP, UMP, UDP-Glc, Glc-1-P, GlcNAc-1-P, and UDP-GlcNAc, the concentration of the phosphate-magnesium complex is greatly reduced by the change in magnesium ion concentration associated with hypomagnesaem ia. This decrease in magnesium-phosphate complex formation would be expected to lead to decreased activity of glycogen synthase because of the role that AMP plays as an allosteric activator as well as decreasing the activity of phosphorylase $b$ which is allosterically activated by glucose-6-phosphate.

To understand the role that metal binding plays in enzymatic activity we analyzed several known crystal structures of sugar NTs [39-49], GT-As [50-60] and GT-Bs [61-67]. The active site analysis of sugar NT crystal structures revealed the metal ion, $\mathrm{Mg}^{+2}$, ligands to be one to two oxygen atoms from the phosphates and two to three coordinated oxygens from aspartic acid residues from the enzyme in question $[40,48]$. Though not as complex, the coordination of $\mathrm{Mg}^{+2}$ in sugar NTs is similar to the octahedral coordination site of $\mathrm{Mn}^{+2}$ seen in GT-As, where the active site analysis shows two of the coordinating atoms to $\mathrm{Mn}^{+2}$ are oxygens from the $\alpha$ - and $\beta$ - phosphates and three to four coordination sites are direct interactions to the

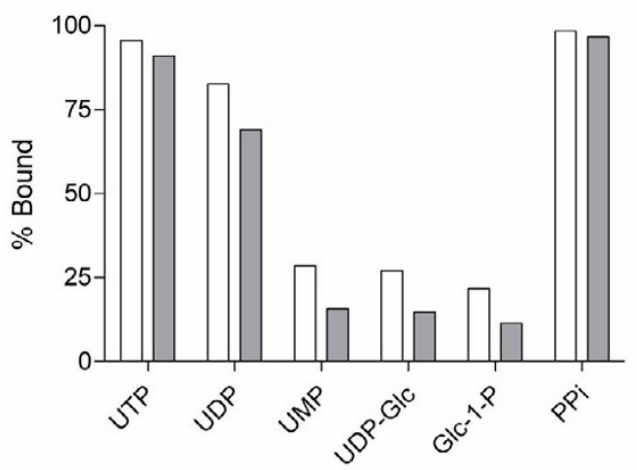

\section{Figure 4}

Percent of phosphate bound to $\mathrm{Mg}^{+2}$ at a normal physiological $\mathrm{Mg}^{+2}$ concentration of $1.5 \mathrm{mM}$ (white) and at a hypomagnesaemia concentration of $0.7 \mathrm{mM}$ (gray).

enzyme [50,52-54], [56-60]. A well-defined metal coordination site in GT-As allows for a high degree of coordination to occur between the metal, $\mathrm{Mn}^{+2}$, and the protein; this fact implies the presence of a permanent metal binding site [54]. This analysis coupled with the fact of a low intracellular concentration of $\mathrm{Mn}^{+2}(10 \mathrm{nM})$ [38] makes the presence of a permanent metal binding site appropriate unless higher local metal concentrations can be maintained at the site of action of particular GTs. The enzymes that constitute GT-Bs, which are not metal dependent, have positively charged amino acid residues, four arginines, which are able to form hydrogen bonds directly to the phosphates [61-67].

\section{Conclusion}

Our findings of no manganese-phosphate complex formation at physiological manganese ion concentration fits previously reported crystal structure determinations demonstrating the presence of a permanent binding site in GTAs for manganese [54]. For highest activity at low manganese concentration, the enzyme would need to have a way to permanently sequester manganese for full biocatalytic function. However for sugar NTs, which are magnesium dependent, the need for a permanent binding site is not required due to the much higher physiological concentration of divalent magnesium in healthy cells. As for inhibitors of sugar NTs, free UTP has been shown to be an inhibitor of Mg-UTP [35], and explains why UDP is an inhibitor in the presence of $\mathrm{Mg}^{+2}$ while it was found not to bind to the enzyme in the absence of a divalent metal [35]. 
The role magnesium plays in the formation of metalphosphate complexes may shed some light in why magnesium chloride therapy has lead to a decrease in serum glucose levels in patients with type 2 diabetes [20-23]. With the increase of the serum $\mathrm{Mg}^{+2}$ concentrations, there will be an increase in the formation of magnesium-phosphate complexes. The complexes formed play a critical role by activating the biocatalysts involved in the manner in which glucose is biochemically stored and released. The decrease in biocatalyst function would not allow for the biochemical pathway to function properly, adequately sequestering glucose as glycogen when glucose levels are high and degrading glycogen when glucose levels are low. Obviously, these implications await human trials now that the basic biochemical data is available.

Knowledge of the method in which the metal binds to the substrate can also play an important role in drug design. When contemplating inhibitor design for sugar NTs, one must design the inhibitor such that it is able to compete against the most prevalent form of the substrate, which for this class of enzymes is the NTP- $\mathrm{Mg}^{+2}$ complex. According to our results, the metal cation binds to NTP first and then after the reaction it leaves bound to $\mathrm{PP}_{i}$. In contrast, in designing inhibitors for glycosyltransferases, one needs to account for the binding that occurs between the manganese and the substrate because manganese is likely to be permanently bound in the active site and important in the catalytic activity of GT-As while not being important for the catalytic activity of GT-Bs. This knowledge of metal affinities therefore may aid in the development of drug candidates that are able to selectively inhibit one class of glycosyltransferases and phosphorylases over another and ultimately also may lead to diabetic drug development [25-28].

\section{Experimental}

2-[4-(2-hydroxyethyl)-1-piperazinyl]-ethanesulfonic acid (Hepes), tetrasodium pyrophosphate decahydrate, magnesium chloride, and manganese (II) chloride were all purchased from Fischer Scientific Company (Hanover Park, IL). All other compounds were purchased from Sigma Chemical Co. (St. Louis, MO) unless otherwise noted and used without further purification. Nanopure water $(18.1 \mathrm{MHz})$ prepared from a Barnstead E-pure water purification system was employed throughout.

\section{Isothermal titration calorimetry}

ITC experiments were performed on a Microcal VP-ITC microcalorimeter (Northampton, MA) which was calibrated using the built-in electrical calibration check. All ITC experiments were conducted in $100 \mathrm{mM}$ Hepes buffer $\mathrm{pH} 7.5$ at $37^{\circ} \mathrm{C}$. Nucleotide phosphate concentration was determined spectrophotometrically from UV absorbance measurements at $262 \mathrm{~nm}$ using an extinction coefficient of $\varepsilon_{262}=20,000 \mathrm{~cm}^{-1} \mathrm{M}^{-1}$ [68]. Glucose-1-phosphate concentrations were determined via electrospray ionization mass spectrometry (ESI-MS) [69]. All solutions were degassed immediately prior to use. Titrant solution $(2.5$, 7.5 , or $10 \mu \mathrm{L}$ ) was added from a $300 \mu \mathrm{L}$ microsyringe at an interval of $200 \mathrm{sec}$. into the stirred sample cell $(1.4288$ $\mathrm{mL}$ ) containing the nucleotide phosphate at a stirring rate of $480 \mathrm{rpm}$. To correct for heats of dilution, control experiments were performed by making identical injections of the titrant solution into a cell containing only buffer and these values were subtracted from the titration of the titrant solution into the reaction cell. The titrant solution contained the metal, $\mathrm{Mg}^{+2}$ or $\mathrm{Mn}^{+2}(75 \mathrm{mM})$, in Hepes buffer (100 mM, pH 7.5). The reaction cell contained 2.5 - $7.5 \mathrm{mM}$ substrate (UTP, UDP, UMP, UDP-Glc, Glc-1-P, Glc, $\mathrm{U}$, or $\left.\mathrm{PP}_{i}\right)$ in Hepes buffer $(100 \mathrm{mM}, \mathrm{pH}$ 7.5). Data was analyzed using nonlinear least-squares curve fitting in Origin (7.0, OriginLab Corp., Northampton, MA) using the standard one binding site model supplied by Origin. This analysis yielded the thermodynamic parameters $K$ (binding constant), enthalpy of binding $(\Delta \mathrm{H})$, entropy of binding $(\Delta S)$, and $n$, where $n$ is the ratio of the metal ion to the substrate in the complex. See Additional file 1 for Isothermal titration calorimetry plots and tables containing $n, K, \Delta \mathrm{G}, \Delta \mathrm{H}$, and $\Delta \mathrm{S}$ metal binding information for all substrates and metals and their thermograms.

\section{Abbreviations}

ADP: Adenosine diphosphate; AMP: Adenosine monophosphate; ATP: Adenosine 5'-triphosphate; DNA: Deoxyribonucleic acid; DPA: Diphenylamine reagent; ESI-MS: Electrospray ionization mass spectrometry; G: Free energy of binding [cal/mol]; Glc: Glucose; Glc-1-P: Glucose-1phosphate; GlcNAc: N-Acetylglucosamine; GlcNAc-1-P: N-Acetylglucosamine-1-phosphate; GT-A: Glycosyltransferase type A; GTB: Glycosyltransferase type B; H: Enthalpy of binding [cal/mol]; HDL: High-density lipoproteins; ITC: Isothermal titration calorimetry; K: Binding constant $\left[\mathrm{M}^{-1}\right]$; LDL: Low-density lipoproteins; $\mathrm{n}$ : Ratio of metal to substrate; NT: Nucleotidyltransferase; $\mathrm{PP}_{i: \text { Pyro- }}$ phosphate; S: Entropy of binding [ $\mathrm{cal} / \mathrm{mol} \cdot \mathrm{T}]$; U: Uridine; UDP: Uridine diphosphate; UDP-Glc: UDP-glucose; UDP-GlcNAc: Uridine diphosphate- $N$-Acetylglucosamine; UMP: Uridine monophosphate; UTP: Uridine triphosphate; UV: Ultraviolet spectroscopy

\section{Authors' contributions}

CJZ and GC-U collected ITC data, performed data analysis, and contributed to drafting the manuscript. NLP conceived of the study, participated in its design and coordination and contributed to drafting the manuscript. All authors read and approved the final manuscript. 


\section{Additional material}

\section{Additional file 1}

Isothermal titration calorimetry plots and tables containing $\mathrm{n}, \mathrm{K}, \Delta \mathrm{G}, \Delta H$, and $\Delta S$ metal binding information for all substrates and metals and their thermograms are given in additional file 1 (Table S1-S2, Figure S1-S22). Click here for file

[http://www.biomedcentral.com/content/supplementary/1752153X-2-15-S1.pdf]

\section{Acknowledgements}

We thank V. Frasca (Microcal) for helpful discussions and the Department of Chemistry, the Plant Sciences Institute, and the Herman Frasch Foundation (American Chemical Society) for partial support of this research. This material is based in part upon work supported by the National Science Foundation under CAREER Grant No. 0349 I39. N.L.P. is a Cottrell Scholar of Research Corporation and an Alfred P. Sloan Research Fellow.

\section{References}

I. Herrero LA, Terron A: Complexation in solution of magnesium (II) and cobalt (II) with purine 5'-monophosphates and pyrimide 5'-monophosphates: a potentiometric and calorimetric study. Polyhedron 1998, 17:3825-3833.

2. Hartwig A: Role of magnesium in genomic stability. Mutat Res 200I, 475:II3-I2I.

3. Barton JK: Metal/Nucleic Acid Interactions. In Bioinorganic Chemistry Edited by: Bertini I, Gray HB, Lippard SJ. Valentine JS: University Science Books; 1994:505-5I5.

4. Sigel $\mathrm{H}$ : Metal ion complexes of antivirally active nucleotide analogues. Conclusions regarding their biological action. Chem Soc Rev 2004, 33:191-200.

5. Shanbhag SM, Choppin GR: Thermodynamics of $\mathbf{M g}$ and $\mathbf{C a}$ complexation with AMP, ADP, ATP. Inorg Chim Acta 1987, 138:187-192.

6. Massoud SS, Sigel H: Metal lon Coordinating Properties of Pyrimidine-Nucleoside 5'-Monophosphates (CMP, UMP, TMP) and of Simple Phosphate Monoesters, Including D-Ribose 5'Monophosphate. Establishment of Relations between Complex Stability and Phosphate Basicity. Inorg Chem 1988, 27:1447-I453.

7. Wilson JE, Chin A: Chelation of Divalent Cations by ATP, Studies by Titration Calorimetry. Anal Biochem 1991, 193:16-19.

8. Sigel $\mathrm{H}$ : Metal ion-assisted stacking interactions and the facilitated hydrolysis of nucleoside 5'-triphosphates. Pure Appl Chem 1998, 70:969-976.

9. Herrero LA, Terron A: Interactions in solution of calcium (II) and copper (II) with nucleoside monophosphates: a calorimetric study. J Biol Inorg Chem 2000, 5:269-275.

10. Stumber M, Herrmann C, Wohlgemuth S, Kalbitzer HR, Jahn W, Geyer M: Synthesis, characterization and application of two nucleoside triphosphate analogues, GTPcNH and GTPcF. Eur J Biochem 2002, 269:3270-3278.

11. Bianchi EM, Sajadi SAA, Song B, Sigel H: Stabilities and Isomeric Equilibria in Aqueous Solution of Monomeric Metal Ion Complexes of Adenosine 5'-Diphosphate (ADP') in Comparison with Those of Adenosine 5'-Monophosphate (AMP2. Chem Eur J 2003, 9:88I-892.

12. Vogel HJ, Bridger WA: Phosphorus-3 I Nuclear Magnetic Resonance Studies of the Methylene and Fluoro Analogues of Adenine Nucleotides. Effects of $\mathrm{pH}$ and Magnesium Ion Binding. Biochemistry 1982, $21: 394-401$.

13. Guerrero-Romero F, Rodriguez-Moran M: Low serum magnesium levels and metabolic syndrome. Acta Diabetol 2002, 39:209-213.

14. Volpe SM: Magnesium, the Metabolic Syndrome, Insulin Resistance, and Type 2 Diabetes Mellitus. Crit Rev Food Sci Nutr 2008, 48:293-300.
15. Wolf Fl, Trapani V: Cell (patho)physiology of magnesium. Clinical Science 2008, I I 4:27-35.

16. Pham P-CT, Pham P-MT, Pham SV, Miller JM, Pham P-TT: Hypomagnesemia in Patients with Type 2 Diabetes. Clin J Am Soc Nephrol 2007, 2:366-373.

17. Barbagallo $M$, Dominguez LJ: Magnesium metabolism in type 2 diabetes mellitus, metabolic syndrome and insulin resistance. Arc Biochem Biophys 2007, 458:40-47.

18. Sales $\mathrm{CH}$, Pedrosa LFC: Magnesium and diabetes mellitus: Their relation. Clin Nutr 2006, 25:554-562.

19. Schroder H: Protective mechanisms of the Mediterranean diet in obesity and type 2 diabetes. J Nutr Biochem 2007, 18:149-160.

20. Guerrero-Romero F, Rodriguez-Moran M: Hypomagnesemia, oxidative stress, inflammation, and metabolic syndrome. Diabetes Metab Res Rev 2006, 22:47। -476.

21. Rodriguez-Moran M, Guerrero-Romero F: Oral magnesium supplementation improves insulin sensitivity and metabolic control in type 2 diabetic subjects: a randomized double-blind controlled trial. Diabetes Care 2003, 26: I|47-II52.

22. Guerrero-Romero F, Tamez-Perez HE, Gonzalez-Gonzalez G, Salinas-Martinez AM, Montes-Villarreal J, Trevino-Ortiz JH, RodriguezMoran M: Oral Magnesium supplementation improves insulin sensitivity in non-diabetic subjects with insulin resistance. A double-blind placebo-controlled randomized trial. Diabetes Metab 2004, 30:253-258.

23. Lopez-Ridaura R, Willett WC, Rimm EB, Liu S, Stampfer MJ, Manson JE, Hu FB: Magnesium intake and risk of type 2 diabetes in men and women. Diabetes Care 2004, 27: $134-140$.

24. Rosanoff A, Seelig MS: Comparison of mechanism and functional effects of magnesium and statin pharmaceuticals. J Am Coll Nutr 2004, 23:50IS-505S.

25. Martin WH, Hoover DJ, Armento SJ, Stock IA, McPherson RK, Danley DE, Stevenson RW, Barrett EJ, Treadway JL: Discovery of a human liver glycogen phosphorylase inhibitor that lowers blood glucose in vivo. Proc Natl Acad Sci USA 1998, 95: 1776-I78I.

26. Oikonomakos NG, Schnier JB, Zographos SE, Skamnaki VT, Tsitsanou $\mathrm{KE}$, Johnson LN: Flavopiridol inhibits glycogen phosphorylase by binding at the inhibitor site. I Biol Chem 2000, 275:34566-34573.

27. Treadway JL, Mendys P, Hoover DJ: Glycogen phosphorylase inhibitors for treatment of type 2 diabetes mellitus. Expert Opin Invest Drugs 200I, 10:439-454.

28. Oikonomakos NG, Zographos SE, Skamnaki VT, Archontis G: The I.76 A resolution crystal structure of glycogen phosphorylase b complexed with glucose, and CP32 a potential antidiabetic drug. Bioorg Med Chem 0626, 10:1313-1319.

29. Green TA, Hannah LC: Adenosine diphosphate glucose pyrophosphorylase, a rate-limiting step in starch biosynthesis. Physiologia Plantarum 1998, 103:574-580.

30. Ballicora MA, Iglesias AA, Preiss J: ADP-glucose pyrophosphorylase, a regulatory enzyme for bacterial glycogen synthesis. Microbiol Mol Biol Rev 2003, 67:213-225.

31. Ballicora MA, Iglesias AA, Preiss J: ADP-Glucose Pyrophosphorylase: A Regulatory Enzyme for Plant Starch Synthesis. Photosynth Res 2004, 79:1-24.

32. Bernstein RL, Robbins PW: Control Aspects of Uridine 5'. Diphosphate Glucose and Thymidine 5'-Diphosphate Glucose Synthesis by Microbial Enzymes. J Biol Chem 1965, 240:391-397.

33. Albrecht G], Bass ST, Seifert LL, Hansen RG: Crystallization and Properties of Uridine Diphosphate Glucose Pyrophosphorylase from Liver. J Biol Chem 1966, 24 I:2968-2975.

34. Roach PJ, Warren KR, Atkinson DE: Uridine Diphosphate Glucose Synthase from Calf Liver: Determinants of Enzyme Activity in Vitro. Biochemistry 1975, 14:5445-5450.

35. Elling L: Kinetic Characterization of UDP-Glucose Pyrophosphorylase from Germinated Barley (Malt). Phytochem 1996, 42:955-960.

36. Gillett TA, Levine S, Hansen RG: Uridine Diphosphate Glucose Pyrophosphorylase. J Biol Chem 1971, 246:255I-2554.

37. Csernoch L, Bernengo JC, Szentesi P, Jacquemond V: Measurements of Intracellular MgConcentration in Mouse Skeletal Muscle Fibers with the Fluorescent Indicator Mag-Indo-I. Biophys J 1998, 75:957-967. 
38. Cowan JA: Inorganic Biochemistry: An Introduction VCH Publishers Inc; 1997.

39. Brown K, Pompeo F, Dixon S, Mengin-Lecreulx D, Cambillau C, Bourne Y: Crystal structure of the bifunctional $\mathbf{N}$-acetylglucosamine I-phosphate uridyltransferase from Escherichia coli: a paradigm for the related pyrophosphorylase superfamily. EMBO J 1999, 18:4096-4I07.

40. Blankenfeldt $W$, Asuncion M, Lam JS, Naismith JJ: The structural basis of the catalytic mechanism and regulation of glucose- $I$ phosphate thymydylyltransferase (RmIA). EMBO J 2000, 19:6652-6663.

4I. Barton WA, Lesniak J, Biggins JB, Jeffrey PD, Jiang J, Rajashankar KR, Thorson JS, Nikolov DB: Structure, mechanism and engineering of a nucleotidylyltransferase as a first step toward glycorandomization. Nature Struct Biol 200I, 8:545-55I.

42. Kostrewa D, D'Arcy A, Takacs B, Kamber M: Crystal Structures of Streptococcus pneumoniae N-Acetylglucosamine-I-phosphate Uridyltransferase, GImU, in Apo Form at 2.33A Resolution and in Complex with UDP-N-Acetylglucosamine and $\mathrm{Mg}^{2+}$ at I.6A Resolution. J Mol Biol 200I, 305:279-289.

43. Olsen LR, Roderick SL: Structure of the Escherichia coli GImU Pyrophosphorylase and Acetyltransferase Active Sites. Biochemistry 200I, 40:1913-1921.

44. Peneff $C$, Ferrari $P$, Charrier $V$, Taburet $Y$, Monnier $C$, Zamboni $V$, Winter J, Harnois M, Fassy F, Bourne Y: Crystal structures of two human pyrophosphorylase isoforms in complexes with UDPGIc(Gal)NAc: role of the alternatively spliced insert in the enzyme oligomeric assembly and active site architecture. EMBO / 200I, 20:6191-6202.

45. Sayre PH, Finer-Moore JS, Fritz TA, Biermann D, Gates SB, MacKellar WC, Patel VF, Stroud RM: Multi-targeted Antifolates Aimed at Avoiding Drug Resistance Form Covalent Closed Inhibitory Complexes with Human and Escherichia coli Thymidylate Synthases. J Mol Biol 200I, 3 I3:8|3-829.

46. Sulzenbacher G, Gal L, Peneff C, Fassy F, Bourne Y: Crystal Structure of Streptococcus pneumoniae N-Acetylglucosamine-Iphosphate Uridyltransferase Bound to Acetyl-coenzyme A Reveals a Novel Active Site Architecture. J Biol Chem 200I, 276: II844-II85I.

47. Zuccotti S, Zanardi D, Rosano C, Sturla L, Tonetti M, Bolognesi M: Kinetic and Crystallographic Analyses Support a Sequentialordered Bi Bi Catalytic Mechanism for Escherichia coli Glucose-I-phosphate Thymidylyltransferase. J Mol Biol 200I, 3 | 3:83|-843.

48. Sivaraman J, Sauve V, Matte A, Cygler M: Crystal Structure of Escherichia coli Glucose-I-Phosphate Thymidylyltransferase (RffH) Complexed with dTTP and $\mathbf{M g}^{2+}$. J Biol Chem 2002, 277:442।4-442। 9 .

49. Thoden JB, Ruzicka FJ, Frey PA, Rayment I, Holden HM: Structural Analysis of the HI66G Site-Directed Mutant of Galactose- Iphosphate Uridylyltransferase Complexed with either UDP. glucose or UDP-galactose: Detailed Description of the Nucleotide Sugar Binding Site. Biochemistry 1997, 36: I 2 I 2-1 222.

50. Charnock SJ, Davies GJ: Structure of the Nucleotide-Diphospho-Sugar Transferase, SpsA from Bacillus subtilis, in Native and Nucleotide-Complexed Forms. Biochemistry 1999. 38:6380-6385.

51. Gastinel LN, Cambillau C, Bourne Y: Crystal structures of the bovine b4galactosyltransferase catalytic domain and its complex with uridine diphosphogalactose. EMBO J 1999, I 8:3546-3557.

52. Unligil UM, Zhou S, Yuwaraj S, Sarkar M, Schachter H, Rini JM: X-Ray Crystal Structure of Rabbit N-Acetylglucosaminyltransferase I: catalytic mechanism and a new protein superfamily. $E M B O$ J 2000, 19:5269-5280.

53. Gastinel LN, Bignon C, Misra AK, Hindsgaul O, Shaper JH, Joziasse $\mathrm{DH}$ : Bovine $\alpha$ I,3-galactosyltransferase catalytic domain structure and its relationship with $A B O$ histo-blood group and glycosphingolipid glycosyltransferases. EMBO J 200I, 20:638-649.

54. Persson K, Ly HD, Dieckelmann M, Wakarchuk WW, Withers SG, Strynadka NC]: Crystal structure of the retaining galactosyltransferase LgtC from Neisseria meningitidis in complex with donor and acceptor sugar analogs. Nature Struct Biol 200I, 8:166-175.
55. Boix E, Zhang Y, Swaminathan G], Brew K, Acharya KR: Structural Basis of Ordered Binding of Donor and Acceptor Substrates to the Retaining Glycosyltransferase, $\alpha-1,3$-Galactosyltransferase. J Biol Chem 2002, 277:28310-283।8.

56. Gibbons BJ, Roach PJ, Hurley TD: Crystal Structure of the Autocatalytic Initiator of Glycogen Biosynthesis, Glycogenin. J Mol Biol 2002, 31 9:463-477.

57. Patenaude SI, Seto NO, Borisova SN, Szpacenko A, Marcus SL, Palcic MM, Evans SV: The structural basis for specificity in human ABO(H) blood group biosynthesis. Nature Struct Biol 2002, 9:685-690.

58. Pedersen LC, Darden TA, Negishi M: Crystal Structure of $\beta \mathbf{I , 3 -}$ Glucuronyltransferase I in Complex with Active Donor Substrate UDP-GIcUA. J Biol Chem 2002, 277:2 1869-2I873.

59. Ramakrishnan B, Balaji PV, Qasba PK: Crystal Structure of $\beta I, 4-$ Galactosyltransferase Complex with UDP-Gal Reveals an Oligosaccharide Acceptor Binding Site. J Mol Biol 2002, 318:49|-502.

60. Negishi M, Dong J, Darden TA, Pedersen LG, Pedersen LC: Glucosaminylglycan biosynthesis: what we can learn from the $X$ ray crystal structures of glycosyltransferases GIcATI and EXTL2. Biochem Biophys Res Commun 2003, 303:393-398.

6I. Vrielink A, Ruger W, Driessen HPC, Freemont PS: Crystal structure of the DNA modifying enzyme $\beta$-glucosyltransferase in the presence and absence of the substrate uridine diphosphoglucose. EMBO J 1994, 1 3:34 | 3-3422.

62. Morera S, Imberty A, Aschke-Sonnenborn U, Ruger W, Freemont PS: T4 Phage $\beta$-Glucosyltransferase: Substrate Binding and Proposed Catalytic Mechanism. J Mol Biol 1999, 292:717-730.

63. Ha S, Walker D, Shi Y, Walker S: The $1.9 \AA$ crystal structure of Escherichia coli MurG, a membrane-associated glycosyltransferase involved in peptidoglycan biosynthesis. Protein Sci 2000, 9:1045-1052.

64. Morera S, Lariviere L, Kurzeck J, Aschke-Sonnenborn U, Freemont PS, Janin J, Ruger W: High Resolution Crystal Structures of T4 Phage $\beta$-Glucosyltransferase: Induced Fit and Effect of Substrate and Metal Binding. J Mol Biol 200 I, 3 I I:569-577.

65. Hu Y, Chen L, Ha S, Gross B, Falcone B, Walker D, Mokhtarzadeh M, Walker S: Crystal structure of the MurG:UDP-GIcNAc complex reveals common structural principles of a superfamily of glycosyltransferases. Proc Natl Acad Sci USA 2003, 100:845-849.

66. Lariviere L, Gueguen-Chaignon V, Morera S: Crystal Structures of the T4 Phage $\beta$-Glucosyltransferase and the DI00A Mutant in Complex with UDP-glucose: Glucose Binding and Identification of the Catalytic Base for a Direct Displacement Mechanism. J Mol Biol 2003, 330: 1077-1086.

67. Mulichak AM, Lu W, Losey HC, Walsh CT, Garavito RM: Crystal Structure of Vancosaminyltransferase GtfD from the Vancomycin Biosynthetic Pathway: Interactions with Acceptor and Nucleotide Ligands. Biochemistry 2004, 43:5|70-5।80.

68. O'Neil MJ, Smith A, Heckelman PE, Obenchain JR, Gallipeau JAR, D'Arecca MA, Budavari S: The Merck Index. Merck $200 \mathrm{I}$.

69. Zea CJ, Pohl NL: Kinetic and substrate binding analysis of phosphorylase b via electrospray ionization mass spectrometry: a model for chemical proteomics of sugar phosphorylases. Anal Biochem 2004, 327: I07-II3.

\section{Publish with ChemistryCentral and every} scientist can read your work free of charge

"Open access provides opportunities to our colleagues in other parts of the globe, by allowing anyone to view the content free of charge."

W. Jeffery Hurst, The Hershey Company.

- available free of charge to the entire scientific community

- peer reviewed and published immediately upon acceptance

- cited in PubMed and archived on PubMed Central

- yours - you keep the copyright

Submit your manuscript here:

http://www.chemistrycentral.com/manuscript/
Chemistry Central 